PAPER

\title{
Cognitive profile in CADASIL
}

\section{F Buffon, R Porcher, K Hernandez, A Kurtz, S Pointeau, K Vahedi, M-G Bousser, H Chabriat}

See Editorial Commentary, p 144

J Neurol Neurosurg Psychiatry 2006;77:175-180. doi: 10.1136/jnnp.2005.068726

See end of article for authors' affiliations

......................

Correspondence to:

Professor Hugues Chabriat,

Hôpital Lariboisière, 2 rue

Ambroise Paré, 75010 ,

Paris, France; hugues.

chabriat@lrb.ap-hop-

paris.fr

Received 29 March 2005

Revised version received

18 June 2005

Accepted 20 June 2005
Background: The spectrum of cognitive alterations associated with CADASIL, a model of pure vascular dementia, has not been thoroughly evaluated.

Objectives: The aims of this study were: (i) to describe the cognitive profile in CADASIL patients according to age; (ii) to compare the profile of patients with dementia with that of patients without dementia; and (iii) to determine the association between alterations in performance in different cognitive domains.

Methods: Forty two consecutive individuals with CADASIL (35-73 years old) were investigated. Cognitive skills were analysed in five domains (executive functions, reasoning, attention, memory, visuospatial abilities) according to age and compared between patients with and without dementia. Associations between cognitive performance and stroke were tested.

Results: The youngest patients presented with attention (69\%), memory $(70 \%)$, and executive disturbances (100\%). Visuospatial abilities and reasoning deteriorated with age, mainly after the age of 60 . About one quarter of patients had dementia, and $75 \%$ of these were $>60$ years of age. Age $>60$ years was associated with a Rankin score $>3$ and a significant deficit in all cognitive domains. No association was found between dementia and the number of ischaemic attacks. Episodic memory disorder was characterised by difficulties in retrieval rather than impairment of the encoding process.

Conclusion: Cognitive decline in CADASIL is dominated by early impairment of executive functions. Skills in other cognitive domains deteriorate with age and are found to be diffusely impaired in patients with dementia. The relative preservation of the encoding process in episodic memory impairment, even in individuals with dementia, is noteworthy.
C erebral autosomal dominant arteriopathy with subcortical infarcts and leukoencephalopathy (CADASIL) is an inherited small vessel disease of the brain caused by mutations in the Notch 3 gene on chromosome 19. ${ }^{1}$ CADASIL is responsible for diffuse white matter changes easily detected on T2 weighted MRI. These signal abnormalities are associated with small deep infarcts in two thirds of cases. ${ }^{2}$ The clinical phenotype of CADASIL includes migraine with aura, subcortical ischaemic stroke, mood disturbances, and cognitive decline. Dementia is usually diagnosed at the end stage of the disorder, most often in association with motor disability, pseudobulbar palsy, and sphincter incontinence. Significant cognitive alterations can be detected in symptomatic patients long before the occurrence of stroke or dementia. Most often, such alterations involved executive functions, attention, and working memory. ${ }^{3-5}$ Both acute stepwise and progressive cognitive decline have been reported in CADASIL patients. ${ }^{6}$ Some authors have suggested that the occurrence of ischaemic lesions in basal ganglia may be of crucial importance in disease progression. However, little is known about the spectrum of cognitive deficits detected in this disorder. In the present study, we aimed: (i) to describe the profile of cognitive alterations in CADASIL patients according to age; (ii) to compare the profile of cognitive performance of patients with dementia with that of patients without dementia; and (iii) to describe how alterations in performance within different domains are associated with each other in this disorder.

\section{METHODS}

\section{Subjects}

Patients included in the study had a diagnosis of CADASIL confirmed by genetic testing showing stereotyped mutations in the Notch 3 gene. ${ }^{1}$ Neuropsychological skills were investigated in a quiet room by an experienced neuropsychologist (AK or KH) from 1994 to 2002 using a standardised psychometric battery. The occurrence of migraine with or without aura, seizures, sphincter disturbances, mood disturbances, and ischaemic manifestations was systematically assessed by a neurologist (FB, HC, KV, or MGB). A complete neurological examination was performed the day before the cognitive evaluation in all subjects and disability was then rated using the Rankin Scale. ${ }^{7}$

\section{Neuropsychological assessment}

The cognitive examination included the following tests: the Weschler Adult Intelligence Scale-Revised (WAIS-R) (similarities, block design, code, digit span, vocabulary, information), semantic and letter verbal fluency, Raven Progressive Matrices (PM38 or 47 according to age), Trail Making Test A and B, the Wisconsin Card Sorting Test revised by Nelson, Rey's complex figure (copy and memory), and the Weschler Memory Scale (from 1994 to 1996), which was replaced by the Grober and Buschke procedure after 1996. ${ }^{2-16}$ Mood disturbances were evaluated using the MADRS scale of depression. ${ }^{17}$ Dementia was diagnosed based on DSM-IV criteria. ${ }^{18}$ Patients were considered to have dementia when: (i) they presented altered cognitive performance in memory in association with altered executive functions or aphasia, apraxia, and/or agnosia, confirmed by the neuropsychological evaluation; or (ii) their relatives confirmed changes in the activities of daily life with a clear decline compared to the previous level of functioning.

\section{Statistical analysis}

Performances in each test (except for the Raven Progressive Matrices, already expressed using percentiles) and for each

Abbreviations: CADASIL, cerebral autosomal dominant arteriopathy with subcortical infarcts and leukoencephalopathy; MCA, multiple correspondence analysis; WAIS-R, Weschler Adult Intelligence ScaleRevised 
Table 1 Patient clinical characteristics according to age

\begin{tabular}{|c|c|c|c|c|}
\hline & \multicolumn{3}{|l|}{ Age (years) } & \multirow{2}{*}{$\mathbf{p}^{*}$} \\
\hline & $<50$ & $50-60$ & $>60$ & \\
\hline Number of patients & $13(31 \%)$ & $14(33 \%)$ & $15(36 \%)$ & \\
\hline $\begin{array}{l}\text { Migraine without } \\
\text { aura, } \mathrm{n}(\%)\end{array}$ & $5(38 \%)$ & 7 (54\%) & $5(36 \%)$ & 0.72 \\
\hline Migraine with aura, $\mathrm{n}(\%)$ & $4(31 \%)$ & $3(27 \%)$ & $4(29 \%)$ & 1.00 \\
\hline $\begin{array}{l}\text { Moderate or severe mood } \\
\text { disturbances, } n(\%)\end{array}$ & $7(54 \%)$ & $4(31 \%)$ & $4(29 \%)$ & 0.38 \\
\hline TIA, n (\%) & $4(31 \%)$ & $5(38 \%)$ & $6(43 \%)$ & 0.97 \\
\hline Stroke, n (\%) & 7 (54\%) & $6(46 \%)$ & $9(64 \%)$ & 0.74 \\
\hline Seizures, n (\%) & $1(8 \%)$ & $3(23 \%)$ & $3(21 \%)$ & 0.67 \\
\hline $\begin{array}{l}\text { Sphincter disturbances, } \\
\text { n (\%) }\end{array}$ & $0(0 \%)$ & $2(15 \%)$ & $4(29 \%)$ & 0.13 \\
\hline Pseudobulbar palsy, n (\%) & $0(0 \%)$ & $3(23 \%)$ & $2(14 \%)$ & 0.28 \\
\hline Rankin score, mean (SD) & $1.0(1.2)$ & $1.2(1.2)$ & $2.2(1.3)$ & $0.037 \dagger$ \\
\hline Rankin score $\geqslant 3, \mathrm{n}(\%)$ & $2(15 \%)$ & $2(15 \%)$ & $7(50 \%)$ & 0.079 \\
\hline Patients with dementia & $2(15 \%)$ & $1(7 \%)$ & $9(60 \%)$ & 0.0047 \\
\hline
\end{tabular}

*Fisher's exact test except for †Kruskal-Wallis test.

patient were converted into $\mathrm{z}$ scores using normative data reported in the literature (WAIS-R, Raven Progressive Matrices, Trail Making Test, Rey's complex figure, Grober and Buschke procedure (unpublished data from Van Der Linden), Weschler Memory Scale, verbal fluency, Wisconsin Card Sorting Test) and data from healthy populations obtained in current clinical practice using normal procedures. ${ }^{12}{ }^{19-23}$ In each case, both age and educational level were considered when converting. Any z scores less than -2 were considered to indicate altered performance except for the percentage of errors in the Wisconsin Card Sorting Test and for the Trail Making Test for which z scores greater than 2 were considered to be abnormal. For the Raven Progressive Matrices the threshold was taken at the 97.5th percentile. When a subtest was not feasible because cognitive alteration was too severe in a given patient, the patient was considered to have altered performance for this subtest. These data were not considered in the calculation of the mean $\mathrm{z}$ scores.

For analysis, the results of the different subtests were grouped into five cognitive domains to best illustrate the pattern of cognitive impairment in the different patients:

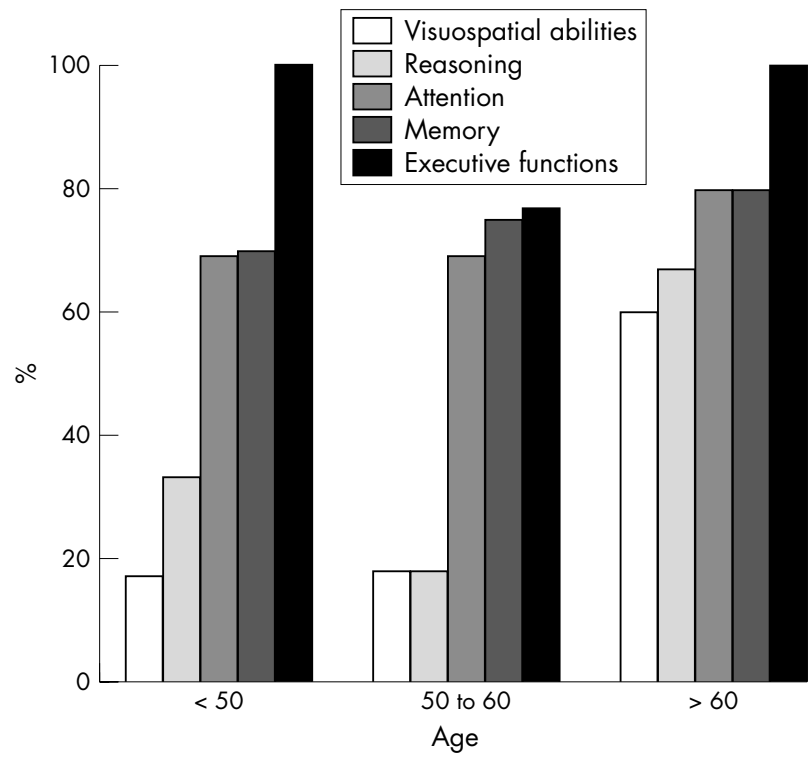

Figure 1 Frequency of altered cognitive performance in each domain for different age categories. The frequency of altered performance increased with age for visuospatial abilities $(p<0.031)$ and reasoning $(p<0.039)$. executive functions (verbal fluency, Trail Making Test B, Wisconsin Card Sorting Test, WAIS-R block design and similarities), reasoning (WAIS-R block design and similarities, Raven progressive matrices PM38 and 47), attention (WAIS-R digit span and code, Trail Making Test A and B), memory (Rey's figure memory, Grober and Buschke procedure, WAIS-R vocabulary and information), and visuospatial abilities (Rey's figure copy, WAIS-R block design, Weschler Memory Scale visual reproduction). ${ }^{11}$ If a patient had impaired performances in any test exploring a specific cognitive domain, they were considered to have altered cognitive performance in that domain.

The patients were divided into three age categories $(<50$, $50-60,>60$ years) of approximately equal sizes.

The association between $\mathrm{z}$ scores and age categories was tested using one way analysis of variance (ANOVA). Associations between cognitive performance and the number of strokes, age category, and clinical manifestations were tested using non-parametric Wilcoxon tests for quantitative variables and $\chi^{2}$ or Fisher's exact tests for qualitative variables.

Multiple correspondence analysis (MCA) was used to graphically assess positive or negative association between performances in the different cognitive domains; MCA provides weighted principal components analysis for multiway tables and supplies a two dimensional representation of the association between different levels of categorical variables. On the graph, a point in the Euclidean space is drawn for each level of the variables, and the distance between any two points is a measure of the strength of association between the two corresponding characters. As in principal components analysis, the axes are selected as best explaining the variability of the observed data. Distance of points from the origin is inversely proportional to the sample size of the corresponding category.

All tests were two sided, at a 0.05 significance level. Analyses were performed using S-Plus 2000 (MathSoft, Seattle, WA) and SAS v8.2 (SAS Institute, Cary, NC) statistical software.

\section{RESULTS}

Main clinical features according to age

Forty two consecutive patients (age range: $35-73$ years) were included in the present study. Their clinical presentation according to age is detailed in table 1 . No significant difference was detected between the three age groups, particularly as regards frequency of pseudobulbar palsy and number of ischaemic strokes. In contrast, the mean Rankin score was twofold higher in patients older than 60 years of age than in other age categories. In addition, $60 \%$ percent of patients older than 60 years of age had dementia, while dementia was diagnosed in only $22 \%$ of subjects below the age of 60 . In the whole series, $12(28.6 \%)$ patients, of whom $75 \%$ were over 60 years of age, met the DSM-IV criteria for dementia.

\section{Impairment of cognitive performance according to age}

Cognitive impairment in patients less than 50 years old most frequently involved the following domains: executive functions (100\%), attention (69\%), and memory (70\%) (fig 1). Altered executive function was detected globally in $87.5 \%$ of individuals. Of the four patients with normal executive functions, three presented with altered memory performance and one without any significant cognitive deficit.

The percentage of patients with altered cognitive performance significantly increased with age for visuospatial ability $(p<0.031)$ and reasoning $(p<0.039)$. The means of $z$ scores for most subtests appeared worse in patients over 60 years of 
Table 2 Mean $\mathrm{z}$ scores obtained in each age category

\begin{tabular}{|c|c|c|c|c|c|c|c|}
\hline & \multicolumn{2}{|c|}{ Age $<50$ years } & \multicolumn{2}{|c|}{ Age $50-60$ years } & \multicolumn{2}{|c|}{ Age $>60$ years } & \multirow[b]{2}{*}{$\mathbf{p}$} \\
\hline & Mean & SD & Mean & SD & Mean & SD & \\
\hline \multicolumn{8}{|l|}{ WAIS-R (z) } \\
\hline Verbal information & -0.4 & 1.8 & 0.3 & 1.2 & -0.1 & 1.2 & 0.64 \\
\hline Digit span & -0.4 & 1 & -0.1 & 1.1 & -0.6 & 1 & 0.71 \\
\hline Similarities & -0.3 & 1.4 & 0.2 & 1.1 & -0.3 & 1.1 & 0.99 \\
\hline Vocabulary & -1.1 & 1.2 & 0.2 & 0.9 & -0.3 & 0.7 & 0.36 \\
\hline Block design & -0.8 & 1.1 & -0.5 & 0.8 & -0.7 & 1.6 & 0.83 \\
\hline Code & -0.9 & 1.1 & -0.6 & 0.8 & -1.6 & 1.3 & 0.094 \\
\hline \multicolumn{8}{|l|}{ Grober-Buschke (z) } \\
\hline Immediate cued recall & 0.4 & 0.4 & -1.2 & 1.7 & -1.1 & 2.3 & 0.090 \\
\hline Free recall (sum of the 3 recalls) & -1.3 & 1.6 & -0.6 & 1.2 & -1.3 & 1.3 & 0.98 \\
\hline Cued recall (sum of the 3 recalls) & 0.9 & 1.1 & 0.8 & 1.4 & 0.8 & 1.1 & 0.88 \\
\hline Recognition & 0 & 0.6 & 0.3 & 0.5 & -1 & 2.8 & 0.23 \\
\hline Delayed free recall & -1.8 & 1.8 & -0.7 & 1.8 & -1.7 & 1.8 & 0.98 \\
\hline Delayed cued recall & 1.6 & 1.6 & 0.8 & 1.9 & 1 & 1.2 & 0.46 \\
\hline \multicolumn{8}{|l|}{ PM38 } \\
\hline Percentile & 56 & 32.3 & 64.5 & 28 & 51.7 & 38.4 & 0.74 \\
\hline \multicolumn{8}{|l|}{ Rey's figure $(z)$} \\
\hline Copy & 0.6 & 2.5 & -0.5 & 5.4 & -3.1 & 6.3 & 0.058 \\
\hline Memory & 0 & 1.2 & -1.4 & 1.1 & -1.9 & 1.6 & $0.0015^{*}$ \\
\hline \multicolumn{8}{|l|}{ Wechsler memory scale (z) } \\
\hline Mental control & -1.8 & 0.2 & -1.7 & 0.1 & -2 & 0.5 & 0.20 \\
\hline Logical memory & -1.5 & 1 & -1.2 & 0.4 & -1.4 & 0.9 & 0.91 \\
\hline Digit span & 0.1 & 1.4 & -0.3 & 1.1 & -0.4 & 1.5 & 0.45 \\
\hline Visual reproduction & -0.5 & 0.7 & 0.2 & 0.3 & -0.5 & 0.8 & 0.74 \\
\hline Paired words & 0.1 & 1.2 & 0 & 1.4 & -1 & 1.6 & 0.11 \\
\hline TMT $(z)$ & 1.6 & 1.9 & 1.8 & 1.1 & 0.6 & 1.9 & 0.32 \\
\hline Time A & 0.6 & 1.4 & 0 & 0.8 & 0.7 & 2.3 & 0.96 \\
\hline Errors A & 0.6 & 1.7 & -0.4 & 0 & 2.7 & 7.5 & 0.27 \\
\hline Time B & 1.8 & 2.2 & 1.6 & 2.3 & 1.1 & 2.5 & 0.53 \\
\hline Errors B & 1.4 & 2.2 & 1.5 & 2.8 & 1.8 & 4.2 & 0.83 \\
\hline \multicolumn{8}{|l|}{ Verbal fluency (z) } \\
\hline Semantic fluency & -1.6 & 0.6 & -1.5 & 0.7 & -2.3 & 0.9 & $0.021^{*}$ \\
\hline Letter fluency & -1.1 & 1.1 & -0.7 & 1.3 & -1.7 & 1.1 & 0.20 \\
\hline \multicolumn{8}{|l|}{ Wisconsin $(z)$} \\
\hline Completed criteria & -0.4 & 0.6 & -0.3 & 0.5 & -0.7 & 0.4 & 0.25 \\
\hline Percentage of errors & 3.6 & 2.3 & 2.3 & 2.6 & 4.1 & 1.3 & 0.78 \\
\hline MADRS (mean value) & 11.8 & 6.9 & 9.5 & 7.5 & 11.9 & 7.2 & 0.94 \\
\hline
\end{tabular}

age than in younger subjects but the difference reached statistical significance only for semantic verbal fluency $(p=0.021)$ and visual memory $(p=0.0015)$.

For all patients irrespective of age, mean $\mathrm{z}$ scores were between -1 and -2 for both verbal (tested using the Grober and Buschke procedure) and non-verbal (tested using Rey's figure) episodic memory. The Grober and Buschke test revealed mild impairment in the encoding process (mean $\mathrm{z}$ scores from -0.6 to -1.3 ) with a significant improvement in spontaneous recall with cues associated with relatively intact recognition (table 2). A trend for intrusion errors $(42.3 \%$ for the first recall and $11.5 \%$ for the third recall) was detected during free recall, independent of age and degree of

Table 3 Association between cognitive skill and symptomatic ischaemic stroke

\begin{tabular}{|c|c|c|c|}
\hline & $\begin{array}{l}\text { No stroke, } \\
n=18\end{array}$ & $\begin{array}{l}\text { Ischaemic } \\
\text { stroke, } \\
n=22\end{array}$ & $\mathbf{p}$ \\
\hline Reasoning & $5(33 \%)$ & $10(48 \%)$ & 0.5 \\
\hline Attention & 10 (59\%) & $18(82 \%)$ & 0.16 \\
\hline \multicolumn{4}{|l|}{ Memory } \\
\hline Non-verbal episodic memory & $7(39 \%)$ & $10(48 \%)$ & 0.75 \\
\hline Verbal episodic memory & $6(40 \%)$ & $9(75 \%)$ & 0.12 \\
\hline Semantic memory & $1(6 \%)$ & $4(19 \%)$ & 0.35 \\
\hline $\begin{array}{l}\text { Total (non-verbal and/or verbal } \\
\text { and/or semantic memory) }\end{array}$ & $11(65 \%)$ & $15(83 \%)$ & 0.26 \\
\hline Visuospatial ability & $2(13 \%)$ & $10(48 \%)$ & $0.04^{*}$ \\
\hline Executive functions & $15(94 \%)$ & $19(90 \%)$ & 1 \\
\hline
\end{tabular}

dementia. Only five patients presented with alterations in semantic memory.

\section{Impairment of cognitive performance and occurrence of stroke}

Performance in the different domains did not differ between patients with or without a history of ischaemic events except for visuospatial ability which was significantly more impaired in patients with one or more strokes $(p=0.04)$ (table 3 ).

\section{Cognitive profile in patients with and without dementia}

Comparison of patients with and without dementia showed that reasoning was impaired more frequently in those with dementia $(p<0.012)$. Neither the frequency of ischaemic attacks nor the age at first stroke differed between these two groups of patients (tables 4 and 5).

\section{Relationship of cognitive profile with age, disability, and ischaemic manifestations}

The MCA illustrated in fig 2 shows that neither memory nor executive functions were associated with age in the present series. In contrast, age $>60$ years was associated with a Rankin score $>3$ and diffuse impairment involving all five cognitive domains. Conversely, age $<50$ years was associated with preserved memory and visuospatial performance (fig 2). The cognitive pattern appeared heterogeneous in patients aged $\leqslant 60$ years and more homogeneous in those $>60$ years.

MCA shows that the strokes were associated with impairment in different cognitive functions and that absence 
Table 4 Comparison of performance in neuropsychological subtests between patients without and with dementia

\begin{tabular}{|c|c|c|c|}
\hline & $\begin{array}{l}\text { Patients } \\
\text { without } \\
\text { dementia, } \\
n=30\end{array}$ & $\begin{array}{l}\text { Patients } \\
\text { with } \\
\text { dementia, } \\
n=12\end{array}$ & $\mathbf{p}$ \\
\hline \multicolumn{4}{|l|}{ WAIS-R } \\
\hline Verbal information & $3 / 29(10 \%)$ & $2 / 12(17 \%)$ & 0.62 \\
\hline Digit span & $1 / 29(3 \%)$ & $3 / 12(25 \%)$ & 0.068 \\
\hline Similarities & $1 / 30(3 \%)$ & $1 / 12(8 \%)$ & 0.49 \\
\hline Vocabulary & $0 / 14(0 \%)$ & $3 / 5(60 \%)$ & $0.01^{*}$ \\
\hline Block design & $3 / 27(11 \%)$ & $5 / 11(45 \%)$ & $0.031^{*}$ \\
\hline \multicolumn{4}{|l|}{ Grober-Buschke } \\
\hline $\begin{array}{l}\text { Immediate cued } \\
\text { recall }\end{array}$ & $4 / 21(19 \%)$ & $3 / 7(43 \%)$ & 0.32 \\
\hline $\begin{array}{l}\text { Free recall (sum of } \\
\text { the } 3 \text { recalls) }\end{array}$ & $2 / 21(10 \%)$ & $6 / 7(86 \%)$ & $0.00048^{*}$ \\
\hline $\begin{array}{l}\text { Cued recall (sum of } \\
\text { the } 3 \text { recalls) }\end{array}$ & $0 / 21(0 \%)$ & $2 / 7(29 \%)$ & $0.056^{*}$ \\
\hline Recognition & $0 / 20(0 \%)$ & $3 / 7(43 \%)$ & $0.012^{*}$ \\
\hline Delayed free recall & $7 / 21(33 \%)$ & $6 / 7(86 \%)$ & $0.029^{*}$ \\
\hline Delayed cued recall & $0 / 21(0 \%)$ & $2 / 7(29 \%)$ & 0.056 \\
\hline \multicolumn{4}{|c|}{ PM38/47 } \\
\hline Percentile & $3 / 29(10 \%)$ & $6 / 12(50 \%)$ & $0.011^{*}$ \\
\hline \multicolumn{4}{|l|}{ Rey's figure } \\
\hline Copy & $4 / 29(14 \%)$ & $6 / 12(50 \%)$ & $0.04^{*}$ \\
\hline Memory & $12 / 29(41 \%)$ & $7 / 12(58 \%)$ & 0.49 \\
\hline \multicolumn{4}{|l|}{$\begin{array}{l}\text { Wechsler memory } \\
\text { scale }\end{array}$} \\
\hline Mental control & $4 / 15(27 \%)$ & $4 / 8(50 \%)$ & 0.37 \\
\hline Logical memory & $0 / 14(0 \%)$ & $3 / 8(38 \%)$ & $0.036^{*}$ \\
\hline Digit span & $0 / 16(0 \%)$ & $1 / 9(11 \%)$ & 0.36 \\
\hline Visual reproduction & $1 / 14(7 \%)$ & $3 / 8(38 \%)$ & 0.12 \\
\hline Paired words & $0 / 14(0 \%)$ & $2 / 5(40 \%)$ & 0.058 \\
\hline \multicolumn{4}{|l|}{ TMT } \\
\hline Time A & $4 / 29(14 \%)$ & $5 / 12(42 \%)$ & 0.093 \\
\hline Errors A & $3 / 29(10 \%)$ & $6 / 12(50 \%)$ & $0.011^{*}$ \\
\hline Time B & $15 / 29(52 \%)$ & $8 / 12(67 \%)$ & 0.5 \\
\hline Errors B & $10 / 29(34 \%)$ & $8 / 12(67 \%)$ & 0.087 \\
\hline \multicolumn{4}{|l|}{ Verbal fluency } \\
\hline Semantic fluency & $9 / 29(31 \%)$ & 10/12 (83\%) & $0.0047^{*}$ \\
\hline Letter fluency & $5 / 28(18 \%)$ & $8 / 12(67 \%)$ & $0.0075^{*}$ \\
\hline \multicolumn{4}{|l|}{ Wisconsin } \\
\hline Completed criteria & $2 / 28$ (7\%) & $4 / 10(40 \%)$ & $0.031^{*}$ \\
\hline Percentage of errors 1 & 18/25 (72\%) & $9 / 10(90 \%)$ & 0.39 \\
\hline $\begin{array}{l}\text { MADRS (threshold } \\
\text { value }>22 \text { ) }\end{array}$ & $3 / 28(11 \%)$ & $3 / 12(25 \%)$ & 0.34 \\
\hline
\end{tabular}

of stroke was associated with age $<50$ years and preserved visuospatial as well as motor abilities (Rankin score $<3$ ).

\section{DISCUSSION}

In this study, we found that: (i) the cognitive profile in CADASIL patients is heterogeneous and involves only a few cognitive domains at the onset of the disease, while it is homogeneous after the age of 60 with significant deficits in all cognitive domains; (ii) patients with dementia have additional impairment in skills such as reasoning compared to subjects without dementia; and (iii) memory impairment even at the late stage of the disorder does not involve the encoding process (retrieval significantly improved with cues) which is relatively preserved compared to that reported in other types of dementia with degeneration of the hippocampus.

The pattern of cognitive impairment clearly differs between younger patients and those more than 60 years of age. In the youngest individuals, the results of this study are in line with previous reports of early cognitive impairment in CADASIL predominately involving executive skills. ${ }^{5}$ Alteration of executive functions was the most frequent cognitive deficit in patients under 50 years of age and was globally detected in almost $90 \%$ of individuals in the present series. In the
Table 5 Comparison of cognitive function between patients without and with dementia

\begin{tabular}{|c|c|c|c|}
\hline & $\begin{array}{l}\text { Without } \\
\text { dementia, } \\
n=30\end{array}$ & $\begin{array}{l}\text { With } \\
\text { dementia, } \\
n=12\end{array}$ & $\mathbf{p}$ \\
\hline $\begin{array}{l}\text { Number of strokes, } \\
\text { median (range) }\end{array}$ & $1(0-4)$ & $2(0-4)$ & 0.30 \\
\hline $\begin{array}{l}\text { Age at first ischaemic } \\
\text { event, median (range) }\end{array}$ & $46(31-62)$ & $50(28-67)$ & 0.81 \\
\hline Reasoning & $7(27 \%)$ & $9(75 \%)$ & $0.012^{*}$ \\
\hline Attention & $19(66 \%)$ & $11(92 \%)$ & 0.13 \\
\hline \multicolumn{4}{|l|}{ Memory } \\
\hline $\begin{array}{l}\text { Verbal episodic memory } \\
\text { Total (non-verbal and/or } \\
\text { verbal and/or } \\
\text { semantic memory) }\end{array}$ & $\begin{array}{r}9(45 \%) \\
18(69 \%)\end{array}$ & $\begin{array}{r}6(86 \%) \\
10(91 \%)\end{array}$ & $\begin{array}{l}0.091 \\
0.23\end{array}$ \\
\hline Visuospatial ability & $6(23 \%)$ & $7(58 \%)$ & 0.064 \\
\hline Executive functions & $25(89 \%)$ & $11(100 \%)$ & 0.55 \\
\hline
\end{tabular}

youngest patients, this deficit was frequently associated with a decline in attention and memory performance compatible with some degree of dysfunction in subcortical-frontal networks. ${ }^{24-26}$ In subjects more than 60 years of age $(60 \%$ of whom had dementia), cognitive impairment appeared more homogeneous than in younger subjects, with significant alterations in all cognitive domains. This extension of cognitive deficits cannot be ascribed only to the deterioration of executive skills affecting functions such as reasoning through the loss of attention, working memory, planning capacities, abstraction, or categorisation. The high frequency of associated impairment in instrumental activities such as language (vocabulary) or in visuospatial abilities in patients older than 60 suggests a diffuse cortical dysfunction well beyond the subcortical-frontal circuits.

In this series, dementia was diagnosed in almost one third of patients and most with dementia were older than 60 years of age. The results showed that by then cognitive impairment was extensive involving not only executive functions, attention and memory but also reasoning and language

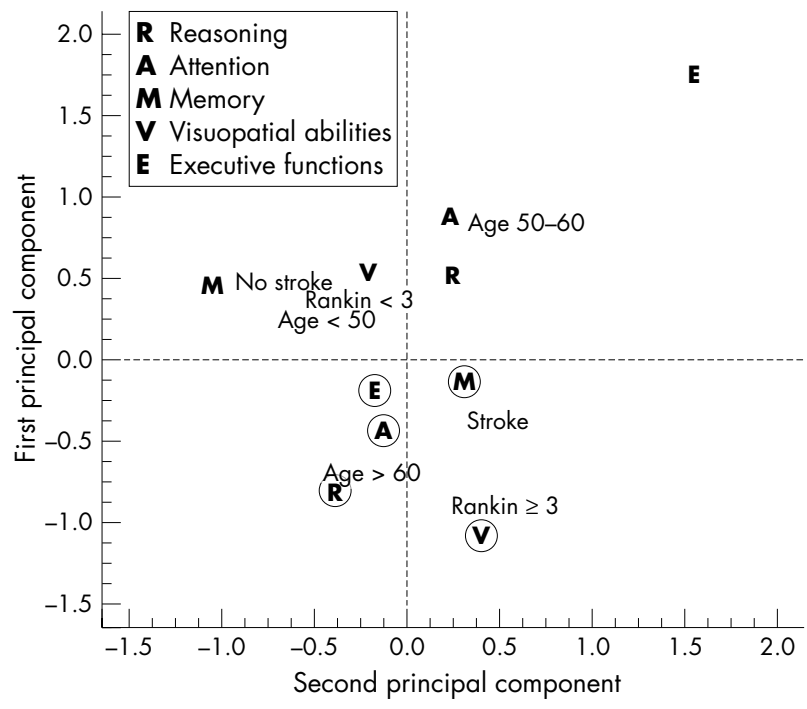

Figure 2 Multiple correspondence analysis performed in the 42 patients. Cognitive functions are represented by their initials which are encircled if the function is impaired. Stroke: symptomatic stroke; no stroke: absence of symptomatic stroke. The figure shows that age $>60$ was associated with impairment in all cognitive functions. The absence of impairment in executive functions appears very rare. 
performance. Dementia was also strongly associated with severe motor disability at the late stage of CADASIL as previously reported. ${ }^{28-30}$ Altogether, these data support the view that dementia occurs after years of accumulation of subcortical ischaemic insults leading to widespread secondary effects on different cortical networks and functions. Interestingly, we observed that a clinical history of stroke was not associated with dementia but only with visuospatial disability. ${ }^{5}$ In the present series, the number of strokes varied between 0 and 4 , both in patients with and without dementia. This confirms that dementia can occur in CADASIL without stroke, and that the number of symptomatic ischaemic event is not a causal factor as already reported in one third of patients with other types of subcortical vascular dementia. ${ }^{31}$ Other mechanisms are therefore probably involved. The accumulation of so called "silent" infarcts, detected in both asymptomatic and symptomatic CADASIL patients, ${ }^{2}$ has been recently identified as a major risk factor for dementia in longitudinal studies of healthy elderly people. ${ }^{32}$ Vermeer et al suggested that their location might be of crucial importance since they observed that silent thalamic infarcts were associated with a delayed decline in memory performances while infarcts outside the thalamus were related to a decrease in psycho-motor speed. ${ }^{33}$ Alternative hypotheses are progressive increase in axonal loss within abnormal white matter as well as secondary degeneration occurring after focal ischaemic lesions in the subcortical grey matter ${ }^{34}$ or within heteromodal cortical areas. Previous imaging studies suggested a strong correlation between the degree of microstructural loss in subcortical areas and cognitive status in CADASIL. This issue cannot be settled by this study without imaging studies performed at the time of cognitive evaluation. Other investigations will help to assess the complex relationships between the number of infarcts, their location, the degree of white matter loss, the severity of cortical atrophy, and cognitive status in this small vessel disease. ${ }^{35}$

In the present study, we observed that the profile of memory impairment did not significantly change according to the age of patients. It is noteworthy that with the Grober and Buschke tests, negative mean z scores were obtained for immediate and delayed free recalls in the different age categories, but positive $\mathrm{z}$ scores were always found for delayed cued recall. Interestingly, the frequency of impairment in free recall was increased among patients with dementia but never reached $100 \%$. Moreover, improvement of recall with cues in the same evaluation, present in all individuals without dementia, was also observed in about two thirds of patients with dementia. These results suggest that the encoding process is preserved during most stages of the disease. This is observed also with relative preservation of recognition and semantic memory. Such a pattern of memory impairment is clearly distinct from that detected in Alzheimer's disease. ${ }^{27}{ }^{36}{ }^{37}$ It is now recognised that cortical degeneration and atrophy may contribute to dementia and memory impairment in patients with subcortical infarcts and white matter lesions..$^{268-40}$ Mesulam et al reported that important cholinergic denervation predominated in frontal and parietal cortices and but relatively spared the mesiotemporal cortex in a young CADASIL patient with dementia. ${ }^{41}$ The results of the present study also suggest that hippocampal regions are relatively spared in most patients with CADASIL, even those with dementia and significant memory impairment. Thus, the pattern of memory disturbance as detected in most CADASIL patients appears to be mainly subcortical. This is possibly related to interruption of frontalsubcortical loops which can occur at different stages of the disorder with accumulation of ischaemic lesions in strategic areas. ${ }^{40}$
There are various limitations to this study: (i) some data are missing for patients with the most severe dementia for whom complete testing was not possible; this may have led to an underestimation of the mean $\mathrm{z}$ scores in the oldest patients; (ii) tests for memory were modified during the study period (the Grober and Buschke procedure was only used in two thirds of patients), but this heterogeneity may have been compensated for by the overall analysis by large cognitive domains in the study; (iii) the segmentation of large cognitive domains chosen to help understanding of the data is arbitrary and can lead to redundancies and/or artificial divisions of the cognitive process; (iv) we used control data from the literature which were obtained in different samples for the calculation of $\mathrm{z}$ scores, which may limit the interpretation of $\mathrm{z}$ scores within the different domains; and (v) finally, the study was cross-sectional and did not include a detailed MRI evaluation thus restricting interpretation of the neuropsychological data.

Despite these limitations, we think that the results obtained provide a general picture of the spectrum of cognitive deficits in CADASIL from early cognitive impairment with predominant executive dysfunction to late dementia with impairment in multiple cognitive domains and demonstrate that the profile of memory impairment in most cases of CADASIL is clearly distinct from that observed in degenerative disorders primarily involving the mesiotemporal cortex.

\section{Authors' affiliations}

F Buffon, K Hernandez, A Kurtz, S Pointeau, K Vahedi, M-G Bousser, H Chabriat, Department of Neurology, Hôpital Lariboisière, 75010, Paris, France

R Porcher, Department of Biostatistics and Medical Informatics, Hôpital Saint-Lovis, 75010, Paris, France

Competing interests: none declared

\section{REFERENCES}

1 Tournier-Lasserve E, Joutel A, Melki J, et al. Cerebral autosomal dominant arteriopathy with subcortical infarcts and leukoencephalopathy maps to chromosome 19q12. Nat Genet 1993;3:256-9.

2 Chabriat $H$, Levy C, Taillia $H$, et al. Patterns of MRI lesions in CADASIL. Neurology 1998:51:452-7.

3 Taillia H, Chabriat H, Kurtz A, et al. Cognitive alterations in non-demented CADASIL patients. Cerebrovasc Dis 1998;8:97-101.

4 Amberla K, Waljas M, Tuominen S, et al. Insidious cognitive decline in CADASIL. Stroke 2004;35:1598-1602.

5 Filley CM, Thompson LL, Sze Cl, et al. White matter dementia in CADASIL. J Neurol Sci 1999;163:163-7.

6 Peters N, Herzog J, Opherk C, et al. A two-year clinical follow-up study in 80 CADASIL subjects: progression patterns and implications for clinical trials. Stroke 2004;35: 1603-8.

7 Van Swieten JC, Koudstaal PJ, Visser MC, et al. Interobserver agreement for the assessment of handicap in stroke patients. Stroke 1988;19:604-7.

8 Wechsler D. Wechsler memory scale - revised (WMS-R). San Antonio, TX: Psychological Corporation, 1987.

9 Raven JC. Revised manual for Raven's coloured progressive matrices. Windsor, UK: NFER-Nelson, 1982.

10 Reitan RM. Validity of the trail making test as an indicator of organic brain damage. Percept Mot Skills 1958;8:271-6.

11 Lezak M. Neuropsychological assessment, 3rd ed. New York: Oxford University Press, 1995.

12 Nelson HE. A modified card sorting test sensitive to frontal lobe defects. Cortex 1976;12:313-24.

13 Osterrieth P. Le test de copie d'une figure complexe. Arch Psychol 1944;30:206-356

14 Stern R, Singer E, Duke L. The Boston qualitative scoring system for the ReyOsterrieth complex figure: description and interrater reliability. Clin Neuropsychol 1944:8:309-22.

15 Van Der Linden M, Wyns C, Bruyer R, et al. Educational level and cued recall performance in older and young adults. Psycholog Belg 1993;33:37-47.

16 Weschler D. Weschler adult intelligence scale, revised: manual. New York: Harcourt Brace Jovanovich, 1981.

17 Montgomery SA, Asberg M. A new depression scale designed to be sensitive to change. Br J Psychiatry 1979;134:382-9.

18 American Psychiatric Association. Diagnostic and statistical manual of mental disorders - fourth edition (DSM-IV). Washington, DC: American Psychiatric Press, 1994. 
19 Wechsler D. WMS-R: Echelle clinique de mémoire de Weschler-révisée: manuel. Paris: Les Éditions du Centre de Psychologie Appliquée, 1991.

20 Raven J-C. Progressive matrices standard: PMS-T. Paris: Les Éditions du Centre de Psychologie Appliquée, 1982.

21 Heaton RK, Grant I, Matthews CG. Comprehensive norms for an expanded Halstead-Reitan battery: demographic corrections, research findings, and clinical applications. Odessa, FL: Psychological Assessment Resources, 1991.

22 Rey A. Manuel: test de copie et de reproduction de mémoire de figures géométriques complexes. Paris: Les Editions du Centre de Psychologie Appliquée, 1959.

23 Troyer AK. Normative data for clustering and switching on verbal fluency tasks. J Clin Exp Neuropsychol 2000;22:370-8.

24 Cummings JL. Frontal-subcortical circuits and human behavior. Arch Neurol 1993:50:873-80.

25 Alexander GE, DeLong MR, Strick PL. Parallel organization of functionally segregated circuits linking basal ganglia and cortex. Annu Rev Neurosci 1986:9:357-81.

26 Roman G, Erkinjuntti T, Wallin A, et al. Subcortical ischaemic vascular dementia. Lancet Neurol 2002;1:426-36.

27 Graham NL, Emery T, Hodges JR. Distinctive cognitive profiles in Alzheimer's disease and subcortical vascular dementia. J Neurol Neurosurg Psychiatry 2004;75:61-71.

28 Molko N, Pappata S, Mangin JF, et al. Monitoring disease progression in CADASIL with diffusion magnetic resonance imaging: a study with whole brain histogram analysis. Stroke 2002;33:2902-8.

29 Chabriat H, Vahedi K, Iba-Zizen MT, et al. Clinical spectrum of CADASIL: a study of 7 families. Cerebral autosomal dominant arteriopathy with subcortical infarcts and leukoencephalopathy. Lancet 1995;346:934-9.

30 Dichgans M, Mayer M, Uttner I, et al. The phenotypic spectrum of CADASIL: clinical findings in 102 cases. Ann Neurol 1998;44:731-9.
31 Leys D, Erkinjuntti T, Desmond DW, et al. Vascular dementia: the role of cerebral infarcts. Alzheimer Dis Assoc Disord 1999; 13(suppl 3):S38-48

32 Zekry D, Duyckaerts C, Belmin J, et al. The vascular lesions in vascular and mixed dementia: the weight of functional neuroanatomy. Neurobiol Aging 2003;24:213-19.

33 Vermeer SE, Prins ND, den Heijer T, et al. Silent brain infarcts and the risk of dementia and cognitive decline. N Engl J Med 2003;348:1215-22.

34 Molko N, Pappata S, Mangin JF, et al. Diffusion tensor imaging study of subcortical gray matter in CADASIL. Stroke 2001;32:2049-54.

35 Pohjasvaara T, Mantyla R, Salonen O, et al. How complex interactions of ischemic brain infarcts, white matter lesions, and atrophy relate to poststroke dementia. Arch Neurol 2000;57:1295-1300.

36 Tierney MC, Black SE, Szalai JP, et al. Recognition memory and verbal fluency differentiate probable Alzheimer disease from subcortical ischemic vascular dementia. Arch Neurol 2001:58:1654-9.

37 Paulsen JS, Butters N, Sadek JR, et al. Distinct cognitive profiles of cortical and subcortical dementia in advanced illness. Neurology 1995;45:951-6.

38 Cohen RA, Paul RH, OH BR, et al. The relationship of subcortical MRI hyperintensities and brain volume to cognitive function in vascular dementia. $J$ Int Neuropsychol Soc 2002;8:743-52.

39 Fein G, Di Sclafani V, Tanabe J, et al. Hippocampal and cortical atrophy predict dementia in subcortical ischemic vascular disease. Neurology 2000;55:1626-35

40 Capizzano AA, Schuff N, Amend DL, et al. Subcortical ischemic vascular dementia: assessment with quantitative MR imaging and $1 \mathrm{H} M \mathrm{MR}$ spectroscopy. AJNR Am J Neuroradiol 2000;21:621-30.

41 Mesulam M, Siddique T, Cohen B. Cholinergic denervation in a pure multiinfarct state: observations on CADASIL. Neurology 2003;60:1183-5.

\section{1th European Forum on Quality Improvement in Health Care}

26-28 April 2006, Prague, Czech Republic For further information please go to: www.quality.bmjpg.com Book early to benefit from a discounted delegate rate 